\title{
Produtividade de forrageiras utilizadas em rampas de tratamento de águas residuárias da lavagem e despolpa dos frutos do cafeeiro
}

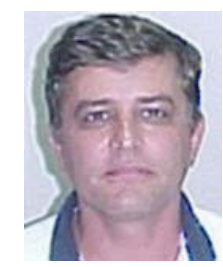

Antonio T. de Matos ${ }^{1}$, Andressa B. Pinto ${ }^{2}$, Odilon G. Pereira ${ }^{3}$, Antonio A. Soares ${ }^{4} \&$ Paola A. Lo Monaco ${ }^{5}$

\author{
1 DEA/UFV. CEP 36571-000, Viçosa, MG. Fone: (31) 3899-1886. E-mail: atmatos@ufv.br (Foto) \\ 2 Engenheira Agrícola, M.S. Fone: (31) 3892-3278. E-mail: abacchetti@bol.com.br \\ 3 DZO/UFV. Fone: (31) 3899-3323. E-mail: odilon@ufv.br \\ ${ }^{4}$ DEA/UFV. Fone: (31) 3899-1908. E-mail: ralves@ufv.br \\ 5 DEA/UFV. Fone: (31) 3891-5701. E-mail: paolalomonaco@bol.com.br
}

Protocolo 135 - 12/9/2002 - Aprovado em 5/2/2003

\begin{abstract}
Resumo: Gramíneas forrageiras foram cultivadas com o objetivo de se selecionar espécies para serem utilizadas como cobertura vegetal em rampas de tratamento de águas residuárias, por escoamento superficial. Essas forrageiras, azevém comum, aveia preta comum e milheto foram submetidas à aplicação de águas residuárias da lavagem e despolpa de frutos do cafeeiro (ARC) sob uma taxa de $250 \mathrm{~kg} \mathrm{ha}^{-1} \mathrm{~d}^{-1}$ de $\mathrm{DBO}_{5}$. As mesmas espécies vegetais foram cultivadas como testemunhas, recebendo adubação convencional e água proveniente da rede de abastecimento local, no mesmo volume em que as demais receberam ARC. Os rendimentos acumulados de matéria seca foram de $11,71,10,04$ e 5,04 t ha-1 e os de proteína bruta, de 1.934, 1.583 e $875 \mathrm{~kg} \mathrm{ha}^{-1}$ para o azevém comum, o milheto e a aveia preta, respectivamente. Os resultados permitiram concluir que, dentre as forrageiras estudadas, o azevém se mostrou mais adequado para ser utilizado em rampas de tratamento de ARC por disposição sobre o solo, visto ter apresentado maior rendimento acumulado de matéria seca e proteína bruta, além de maior número de cortes e, conseqüentemente, maior período de utilização, além de rápida recuperação após o corte, boa cobertura do solo e ocorrência de poucas invasoras.
\end{abstract}

Palavras-chave: água residuária, despolpa do café, escoamento sobre o solo, gramíneas forrageiras

\section{Forage yield in treatment ramps of wastewater from processing of coffee fruits}

\begin{abstract}
Forage grasses were grown in order to select a number of species to be used as vegetative cover on ramps for wastewater treatment. The common rye grass (Lolium multiflorum), common black oat (Avena strigosa Schreb) and pearl millet (Pennisetum americanum) were used and subjected to application of wastewater from the washing and pulping of coffee cherries $(A R C)$ at a rate of $250 \mathrm{~kg} \mathrm{ha}^{-1} \mathrm{~d}^{-1}$ of $\mathrm{BOD}_{5}$. The same vegetative species were grown as control, and provided with conventional fertilization as well as water from the local supplying system receiving similar volume as the others. The accumulated productivities of the dry matter were $11.71,10.04$, and $5.04 \mathrm{t} \mathrm{ha}^{-1}$, while those of the raw protein were 1934, 1583 and $875 \mathrm{~kg} \mathrm{ha}^{-1}$ for common rye grass, pearl millet and common black oat, respectively. The results allow to conclude that the common rye grass was most appropriate to be used on the ramps of the ARC disposed on soil, since it showed a higher accumulated productivity of dry matter and raw protein as well as a higher number of cuttings consenquently a longer period of use apart from faster recovery after cutting, a satisfactory soil covering and the low weed occurrences.
\end{abstract}

Key words: wastewater, pulping of coffee, surface flow, forage grasses

\section{INTRODUÇ̃̃O}

O processamento por via úmida dá origem aos grãos de café lavados/descascados e despolpados, bastante comuns entre os produtores da América Central, México, Colômbia,
Quênia e África, alcançando boas cotações no mercado por proporcionarem, de modo geral, a produção de bebida suave. Embora o Brasil seja conhecido como produtor de grãos de café obtidos por via seca, forma de processamento responsável por cerca de $90 \%$ de sua produção total (Leite e Silva, 2000), 
alguns produtores começam a optar pelo processamento do fruto tipo cereja, descascando-o e, às vezes, retirando sua mucilagem (despolpa), principalmente em regiões montanhosas com boa disponibilidade de água. Neste caso, um problema a ser enfrentado é o destino dos resíduos líquidos e sólidos gerados no processo via úmida do fruto, que começa a ser implantado no País para atender à crescente demanda internacional por grãos de alta qualidade e que proporcionem bebidas finas (Soccol et al., 2000).

O impacto que as águas residuárias da lavagem, descascamento e desmucilagem de frutos do cafeeiro (ARC) causam ao ambiente é grande, pelo enorme volume de água limpa utilizado no processamento do fruto, e pela carga orgânica que essas águas possuem (Campos, 1993) e que podem, desta forma, trazer muitos prejuízos aos corpos d'água receptores. A ARC apresenta demanda bioquímica de oxigênio (DBO) de $1.578 \mathrm{a}$ $3.242 \mathrm{mg} \mathrm{L}^{-1}$, demanda química de oxigênio (DQO) de 3.429 a $5.524 \mathrm{mg} \mathrm{L}^{-1}$ e concentração de N, P e K nas faixas de 185,6 a 245,$5 ; 4,5$ a 6,5 e 44,4 a 346,0 $\mathrm{mg} \mathrm{L}^{-1}$, respectivamente (Matos et. al., 2001).

Dentre as soluções propostas para tratamento de águas residuárias ricas em material orgânico, destaca-se a sua disposição direta sobre o solo, em sistemas de tratamento por escoamento superficial, por ser uma alternativa viável, de baixo custo de implantação e, ainda, por possibilitar o aproveitamento dos nutrientes contidos nessas águas. O objetivo de se utilizar o solo como meio de tratamento de águas residuárias está ligado ao aproveitamento do filtro natural constituído pelas plantas e pelos microrganismos que, juntamente com suas propriedades de adsorção química e física, possibilitam a remoção de material orgânico e inorgânico presentes nesses efluentes (Hubbard et al., 1987).

Conforme Paganini (1997), a eficiência de um sistema de disposição controlada de águas residuárias no solo depende de detalhes e cuidados construtivos, porém é o sistema soloplanta que confere ao tratamento o aspecto de renovação, que evita a exaustão do solo. A vegetação é, então, de fundamental importância na remoção dos nutrientes do solo, evitando seu acúmulo e conseqüente salinização e/ou a contaminação dos aqüíferos subterrâneos, além de favorecer o desenvolvimento de uma película biologicamente ativa (biofilme) que degradará o material orgânico. Soma-se, aos benefícios já citados, o fato do material vegetal produzido poder ser utilizado para alimentação animal, in natura ou ensilado.

Queiroz et al. (2001), avaliando o desempenho de algumas forrageiras de verão em rampas de tratamento de águas residuárias por escoamento superficial, observaram melhor desempenho agronômico do capim Tifton 85, com produtividade acumulada de matéria seca de 17,77 tha-1.

Considerando-se a estacionalidade da colheita e o processamento dos frutos do cafeeiro, torna-se necessária a seleção de espécies forrageiras de inverno de conhecido valor nutritivo, a fim de possibilitar seu aproveitamento na alimentação animal. Neste trabalho, teve-se por objetivo avaliar os rendimentos da matéria seca e da proteína bruta das espécies forrageiras azevém comum (Lolium multiflorum), milheto (Pennisetum americanum) e aveia preta (Avena strigosa schreb).

\section{MATERIAL E MÉTODOS}

O trabalho foi implantado e conduzido em uma área de aproximadamente $350 \mathrm{~m}^{2}$, pertencente à Fazenda Laje, localizada no município de Viçosa na Zona da Mata mineira, MG, a $689,73 \mathrm{~m}$ de altitude, em longitude de $42^{\circ} 52^{\prime} 40^{\prime}$ 'W (Grw) e latitude de $20^{\circ} 45^{\prime} 20^{\prime \prime} \mathrm{S}$.

Para montagem do experimento, utilizou-se o delineamento em blocos casualizados, com quatro repetições, sendo os tratamentos definidos por três espécies forrageiras e duas qualidades de água aplicadas durante o período de cultivo. As espécies forrageiras cultivadas foram azevém comum, aveia preta comum e milheto. As duas qualidades de água aplicadas durante o cultivo das forrageiras foram água residuária da lavagem e despolpa de frutos do cafeeiro (ARC) e água da rede de abastecimento da propriedade agrícola (AA). Somente as parcelas em que foram aplicadas AA receberam adubação química convencional, recomendada para o cultivo de forrageiras, de acordo com a análise química preliminar do solo da área experimental. As adubações foram realizadas 28 dias após a semeadura (DAS) e após cada corte das forrageiras, sendo aplicados $40 \mathrm{~kg} \mathrm{ha}^{-1}$ de $\mathrm{K}_{2} \mathrm{O}$ e $40 \mathrm{~kg} \mathrm{ha}^{-1}$ de $\mathrm{N}$, nas formas de cloreto de potássio e uréia, respectivamente.

No dia 5/5/2000, as espécies forrageiras foram semeadas em parcelas de 3,0 × 2,0 m com espaçamento de $0,20 \mathrm{~m}$ entre linhas de plantio e 1,0 m entre parcelas, em solo com declividade de $5 \%$. As densidades de plantio utilizadas foram de $80 \mathrm{~kg} \mathrm{ha}^{-1}$ para a aveia preta comum, $30 \mathrm{~kg} \mathrm{ha}^{-1}$ para o azevém comum e de $15 \mathrm{~kg} \mathrm{ha}^{-1}$ para o milheto.

As águas residuárias provenientes da lavagem e despolpa de frutos do cafeeiro coletadas em tanque de sedimentação, e as águas da rede de abastecimento da propriedade agrícola foram acondicionadas em tanques de $500 \mathrm{~L}$ e aplicadas nas parcelas, manualmente, com o uso de regadores. Drenos superficiais captaram e conduziram o efluente das parcelas para fora da área experimental.

A aplicação da água residuária ocorreu de segunda a sextafeira, sob uma taxa equivalente a $250 \mathrm{~kg} \mathrm{ha}^{-1} \mathrm{~d}^{-1} \mathrm{de} \mathrm{DBO}_{5}$. Como a determinação da $\mathrm{DBO}_{5}$ só é possível após $5 \mathrm{~d}$ de incubação das amostras de água residuária e se necessitava conhecer seu valor no momento do início da aplicação, o controle da $\mathrm{DBO}_{5}$ da ARC foi baseado em estimativa obtida a partir de cálculos efetuados utilizando-se uma equação matemática que relaciona a condutividade elétrica com a $\mathrm{DBO}_{5}$ da $\mathrm{ARC}$ :

$$
\mathrm{DBO}_{5}=3,5447(\mathrm{CE})^{0,9847}
$$

em que:

$\mathrm{DBO}_{5}$ - demanda bioquímica de oxigênio da ARC determinada após incubação sob temperatura de $20{ }^{\circ} \mathrm{C}$, $\mathrm{mg} \mathrm{L}^{-1}$

$\mathrm{CE} \quad$ - condutividade elétrica da $\mathrm{ARC}, \mu \mathrm{S} \mathrm{cm}^{-1}$

Durante a fase inicial de desenvolvimento das culturas, as gramíneas forrageiras de todas as parcelas experimentais receberam apenas AA e, a partir do dia 5/6/2000, começou a aplicação de $\mathrm{ARC}$ naquelas parcelas experimentais previamente definidas para recebê-las. 
O material vegetal das parcelas experimentais foi cortado aos 68,110 e 150 DAS, épocas em que as plantas atingiram altura de $30 \mathrm{~cm}$ a aproximadamente $8,0 \mathrm{~cm}$ da superfície do solo em uma área útil de $2 \mathrm{~m}^{2}$, após a eliminação de $0,50 \mathrm{~m}$ nas laterais e nas extremidades das parcelas. Os cortes foram feitos manualmente, com o auxílio de um cutelo. Ressalta-se que a aveia preta sofreu um único corte (aos 68 DAS) enquanto no milheto foram feitos dois cortes (110 e 150 dias após semeadura) e o azevém recebeu os três cortes, como pode ser visto na Tabela 1.

Tabela 1. Idade e altura média $(\mathrm{cm})$ das gramíneas forrageiras no dia do corte

\begin{tabular}{lccccc}
$\begin{array}{c}\text { Gramínea } \\
\text { Forrageira }\end{array}$ & $\begin{array}{c}\text { Água }^{\text {Aplicada }}{ }^{1} \\
\text { Aveia preta }\end{array}$ & $\begin{array}{c}\mathrm{DAS}^{2} \\
(\text { dias })\end{array}$ & $\begin{array}{c}\mathrm{AM}^{1} \\
(\mathrm{~cm})\end{array}$ & $\begin{array}{c}\text { Corte } \\
\text { (número) }\end{array}$ & $\begin{array}{c}\text { Dia do } \\
\text { Corte }\end{array}$ \\
\hline Aveia preta & ARC & 68 & 83 & 1 & $12 / 07 / 00$ \\
Azevém comum & AA & 68 & 72 & 1 & $12 / 07 / 00$ \\
Azevém comum & ARC & 68 & 39 & 1 & $12 / 07 / 00$ \\
Azevém comum & AA & 110 & 75 & 2 & $23 / 07 / 00$ \\
Azevém comum & ARC & 110 & 62 & 2 & $23 / 08 / 00$ \\
Azevém comum & AA & 150 & 77 & 3 & $02 / 10 / 00$ \\
Azevém comum & ARC & 150 & 80 & 3 & $02 / 10 / 00$ \\
Milheto & AA & 110 & 108 & 1 & $23 / 08 / 00$ \\
Milheto & ARC & 110 & 92 & 1 & $23 / 08 / 00$ \\
Milheto & AA & 150 & 93 & 2 & $02 / 10 / 00$ \\
Milheto & ARC & 150 & 115 & 2 & $02 / 10 / 00$ \\
\hline 'AA: Água proveniente da rede de abastecimento local; ARC: Água proveniente da lavagem e despolpa \\
de frutos do cafeeiro; AM - Altura média \\
${ }^{2}$ DAS - Dias após a semeadura
\end{tabular}

O material, cortado a cerca de $8,0 \mathrm{~cm}$ da superfície do solo, teve sua biomassa recolhida e pesada no próprio local do experimento, por meio de balança tipo dinamômetro, para determinação da massa verde; em seguida, foram separadas e encaminhadas imediatamente ao Laboratório de Nutrição Animal do Departamento de Zootecnia da UFV, três amostras de, aproximadamente, $300 \mathrm{~g}$ do material de cada parcela experimental, para determinação da pré-secagem. No laboratório, as amostras foram pesadas em balança digital e depois colocadas em estufa com circulação forçada de ar, a $65^{\circ} \mathrm{C}$, pelo período de $72 \mathrm{~h}$, para secagem. Após este período, as amostras foram retiradas da estufa e tiveram sua massa novamente determinada. Este material foi, então, moído em moinho tipo Willey, usando-se peneiras de 30 mesh e acondicionados em recipientes de vidro; depois, aproximadamente $3 \mathrm{~g}$ de cada amostra moída foram secados em estufa a $105^{\circ} \mathrm{C}$, a fim de se corrigir o conteúdo de matéria seca.

O nitrogênio total foi determinado pelo método semimicro Kjeldahl e a conversão de $\mathrm{N}$ para proteína bruta obtida por meio de cálculos (Silva, 1998).

Para análise estatística dos dados de rendimento acumulado de matéria seca e proteína bruta das forrageiras, usou-se um esquema fatorial $3 \times 2$, com três forrageiras e duas qualidades de água, com quatro repetições.

\section{RESULTADOS E DISCUSSÃO}

$\mathrm{Na}$ Tabela 2 estão apresentadas as análises de variância dos rendimentos acumulados de matéria seca (RMS) e de proteína bruta (RPB) das forrageiras avaliadas. Os rendimentos foram diferentes para as forrageiras e a qualidade de água
Tabela 2. Análise de variância do rendimento acumulado de matéria seca (RMS) e do rendimento acumulado de proteína bruta (RPB) das gramíneas forrageiras avaliadas durante o período experimental

\begin{tabular}{lcccccc}
\multirow{2}{*}{ Fontes de Variação } & \multirow{2}{*}{ GL } & \multicolumn{2}{c}{ RMS } & & \multicolumn{2}{c}{ RPB } \\
\cline { 3 - 4 } \cline { 6 - 7 } & & QM & F & & QM & F \\
\hline Blocos & 3 & 16,408 & 7,69 & 869.004 & 7,5 \\
Forrageiras (F) & 2 & 96,526 & $45,26^{* *}$ & 2.328 .640 & $20,10^{* *}$ \\
Qualidade da água (A) & 1 & 15,472 & $7,25^{*}$ & 1.290 .005 & $11,13^{* *}$ \\
(FxA) & 2 & 0,677 & $0,32^{\text {ns }}$ & 23.301 & $0,20^{\text {ns }}$ \\
Resíduo & 15 & 2,133 & & 115.870 & -
\end{tabular}

\begin{tabular}{lll}
\hline C.V. (\%) & 16,4 & 23,2
\end{tabular}

* Significativo ao nível de $5 \%$ de probabilidade pelo teste $\mathrm{F}$

** Significativo ao nível de $1 \%$ de probabilidade pelo teste $\mathrm{F}$

${ }^{\text {ns }}$ Não significativa

afetou, de maneira global, o seu rendimento. O desdobramento da análise estatística do efeito da qualidade da água aplicada no rendimento acumulado de matéria seca e proteína bruta de cada espécie forrageira não foi, entretanto, possível, uma vez que não foi significativa $(\mathrm{p}<0,05)$ a interação entre a qualidade da água e a forrageira.

Nas Tabelas 3 e 4 apresentam-se os resultados das médias dos RMS e RPB, obtidos por cada espécie forrageira, e as médias desses rendimentos obtidas considerando-se apenas a qualidade da água aplicada no cultivo.

Tabela 3. Média dos rendimentos acumulados de matéria seca* obtidos para diferentes forrageiras e pelo grupo de forrageiras quando aplicadas, durante o cultivo, águas de diferentes qualidades

\begin{tabular}{lccc}
\hline \multirow{2}{*}{ Forrageira } & \multicolumn{2}{c}{ Qualidade da Água } & \multirow{2}{*}{ Média } \\
\cline { 2 - 3 } & $\mathrm{AA}^{1}$ & $\mathrm{ARC}^{2}$ \\
\cline { 2 - 3 } & \multicolumn{3}{c}{$\mathrm{t} \mathrm{ha}^{-1}$} \\
\hline Azevém comum & 12,35 & 11,07 & $11,71 \mathrm{a}$ \\
Milheto & 11,18 & 8,90 & $10,04 \mathrm{a}$ \\
Aveia preta & 5,66 & 4,41 & $5,04 \mathrm{~b}$ \\
Médias & $9,73 \mathrm{~A}$ & $8,12 \mathrm{~B}$ \\
\hline
\end{tabular}

${ }_{1}$ Água da rede de abastecimento da propriedade agrícola, com adubação

Água residuária proveniente da lavagem e despolpa de frutos do cafeeiro, sem adubação

Médias seguidas pelas mesmas letras minúsculas, nas colunas, e maiúsculas, nas linhas, não diferem a $5 \%$ de probabilidade, pelo teste de Tukey

Tabela 4. Média dos rendimentos acumulados de proteína bruta* obtidos para diferentes forrageiras e pelo grupo de forrageiras quando aplicadas, durante o cultivo, águas de diferentes qualidades

\begin{tabular}{|c|c|c|c|}
\hline \multirow{3}{*}{ Forrageira } & \multicolumn{2}{|c|}{ Qualidade da Água } & \multirow{2}{*}{ Médias } \\
\hline & $\mathrm{AA}^{1}$ & $\mathrm{ARC}^{2}$ & \\
\hline & \multicolumn{3}{|c|}{$\mathrm{kg} \mathrm{ha}^{-1}$} \\
\hline Azevém comum & $2.116,31$ & $1.752,26$ & $1.934,29 \mathrm{a}$ \\
\hline Milheto & $1.872,28$ & $1.293,93$ & $1.583,11 \mathrm{a}$ \\
\hline Aveia preta & $1.099,42$ & 640,78 & $875,10 \mathrm{~b}$ \\
\hline Médias & $1.696,00 \mathrm{~A}$ & $1.232,32 \mathrm{~B}$ & \\
\hline
\end{tabular}

O RPB indica o quanto desta substância foi acumulado na planta, sendo obtido pelo produto entre a concentração do nitrogênio total e o rendimento da matéria seca em cada corte. 
Em relação às forrageiras estudadas, os maiores rendimentos acumulados de matéria seca e proteína bruta foram obtidos pelo azevém comum, $11,71 \mathrm{tha}^{-1}$ e $1.934,29 \mathrm{~kg} \mathrm{ha}^{-1}$ respectivamente, embora não tenham diferido $(\mathrm{p}<0,05)$ do obtido com o cultivo do milheto (Tabelas 3 e 4). O maior rendimento acumulado de proteína bruta obtido para o azevém foi, provavelmente, decorrente da maior produção de matéria seca $\left(11,71 \mathrm{t} \mathrm{ha}^{-1}\right)$ desta forrageira, visto que o seu teor protéico e o do milheto entre as forrageiras, foi muito semelhante. Ressaltase, no entanto, que o número de cortes foi diferente para as forrageiras, tendo sido realizados um, dois e três cortes para a aveia preta, o milheto e o azevém comum, respectivamente, o que pode, em parte, explicar a maior produtividade acumulada alcançada pela forrageira que sofreu maior número de cortes no período do experimento. $\mathrm{O}$ azevém comum teve melhor comportamento agronômico durante o período experimental, apresentando maior número de cortes e, em conseqüência, maior período de produção de forragem.

Embora o RMS e o RPB de cada forrageira não tenham sido influenciados $(\mathrm{p}<0,05)$ pela qualidade da água aplicada, nas parcelas experimentais onde foram aplicadas ARC, houve tendência do azevém comum apresentar rendimentos acumulados de matéria seca e proteína bruta superiores aos obtidos pelo milheto e pela aveia preta. $\mathrm{O}$ valor médio obtido de rendimento acumulado de matéria seca desta forrageira fertirrigada com ARC (11,07 $\left.\mathrm{t} \mathrm{ha}^{-1}\right)$ superou os encontrados por Moraes et al. (1998) que foi de 6,14 $\mathrm{t} \mathrm{ha}^{-1}$, obtido em quatro cortes no período de inverno/primavera; o obtido por Gomes \& Reis (1999) que foi de 4,4 $\mathrm{t} \mathrm{ha}^{-1}$. ano ${ }^{-1}$, para os anos de $1994 \mathrm{a}$ 1996 no Rio Grande do Sul, e o citado por Flaresso et al. (1998) de $5,15 \mathrm{t} \mathrm{ha}^{-1}$, para plantios efetuados na primeira quinzena de abril. Da mesma forma, o valor médio obtido de rendimento acumulado de proteína bruta desta forrageira fertirrigada com ARC (1.752,26 kg ha $\left.{ }^{-1}\right)$ também superou valores encontrados por Gomes \& Reis (1999) que, avaliando de 1994 a 1996 forrageiras anuais de estação fria, obtiveram $705,16 \mathrm{~kg} \mathrm{ha}^{-1} \mathrm{ano}^{-1}$ de rendimento de proteína bruta para o azevém comum. No mesmo período, esses autores obtiveram, também, 843,39 $\mathrm{kg} \mathrm{ha}^{-1} \mathrm{ano}^{-1}$ de rendimento de proteína bruta para a aveia preta.

Guideli et al. (1998) obtiveram 3,19 e 7,01 tha $\mathrm{th}^{-1}$ de rendimento de matéria seca para o milheto semeado em março, com dois cortes, e para o semeado em novembro, com quatro cortes, respectivamente; valores inferiores aos apresentados no presente trabalho, de 11,18 e de 8,90 tha ${ }^{-1}$ para o milheto irrigado com AA e com ARC, respectivamente. Pereira (1991), trabalhando com o milheto, obteve valor médio de rendimento de proteína bruta de $930 \mathrm{~kg} \mathrm{ha}^{-1}$ corte $^{-1}$, para o plantio tardio, realizado em final do mês de abril. Os valores encontrados no presente trabalho para esta forrageira, fertirrigada com ARC e semeada no início de maio, foram de $1.293,93 \mathrm{~kg} \mathrm{ha}^{-1}$, em dois cortes, o que corresponde a $646,97 \mathrm{~kg} \mathrm{ha}^{-1}$ corte $^{-1}$, resultado inferior ao encontrado pelo citado autor. Os menores RPB encontrados no milheto produzido neste trabalho estão, provavelmente, associados à redução na produção da gramínea, que deve ter ocorrido em virtude da semeadura tardia, evidenciando um efeito negativo do fotoperíodo e da temperatura sobre a cultura na época do ano em que foi cultivada neste experimento.
É oportuno que as culturas utilizadas como cobertura vegetal, em sistema de tratamento de águas residuárias por escoamento superficial, sejam eficientes na remoção de nutrientes do solo, sobretudo de nitrogênio que, quando mineralizado, pode ser transformado em nitrato, ânion de alta mobilidade no solo e que coloca em risco a qualidade das águas subterrâneas. Sob esta lógica, o azevém comum seria uma forrageira adequada a esta finalidade, dado à sua maior capacidade de acumular nitrogênio na forma de proteína bruta, nos seus tecidos.

De acordo com o que está apresentado nas Tabelas 3 e 4, pode-se verificar diferenças $(p<0,05)$ entre as médias dos rendimentos de matéria seca e de proteína bruta das forrageiras, conforme a qualidade de água utilizada em seus cultivos. As maiores médias de rendimento de matéria seca e proteína bruta foram alcançadas quando se utilizou AA, com valores de $1.696,00 \mathrm{~kg} \mathrm{ha}^{-1} \mathrm{e} 9,73 \mathrm{t} \mathrm{ha}^{-1}$, respectivamente, com a aplicação desta qualidade de água, complementada com adubação química durante o cultivo.

Apesar de ter sido obtido menor rendimento quando se aplicou apenas ARC no cultivo que com a aplicação de AA, pode-se dizer que os valores encontrados estiveram próximos, o que não deixa de ser um resultado positivo, visto que não se esperava que este tipo de fertirrigação superasse a irrigação com água de boa qualidade complementada com adubação convencional. É importante não se perder de vista que, como a avaliação das forrageiras é feita para que se possa escolher a espécie que melhor se adapte às condições de cultivo em uma rampa de tratamento de $\mathrm{ARC}$, a produção de forragem não deve ser encarada como o objetivo fim da seleção.

\section{CONCLUSÕES}

1. Dentre as forrageiras estudadas, o azevém mostrou-se mais adequado para ser utilizado em rampas de tratamento de $\mathrm{ARC}$, por disposição sobre o solo, visto ter apresentado maior rendimento acumulado de matéria seca (RMS) e proteína bruta (RPB) apesar de não ter diferido significativamente do rendimento apresentado pelo milheto.

2. O azevém mostrou melhor comportamento durante o período experimental, maior número de cortes e, conseqüentemente, maior período de utilização das forragens, além de rápida recuperação após o corte, boa cobertura do solo e ocorrência de poucas invasoras.

3. As forrageiras que receberam ARC apresentaram rendimento de matéria seca e de proteína bruta muito próximo aos obtidos com a aplicação de água de boa qualidade, complementada com adubação convencional, o que torna a aplicação da ARC no solo opção interessante sob o ponto de vista econômico e ambiental.

\section{AGRADECIMENTOS}

Ao CBP\&D-Café - Consórcio Brasileiro de Pesquisa e Desenvolvimento do Café, pelo apoio financeiro à pesquisa. 


\section{LITERATURA CITADA}

Campos, J.M.C. Contaminación del agua em Costa Rica por residuos del procesamiento del café y de la porcinocultura. In: Campos, J.M.C. Prevención de la contaminación del agua por la agricultura y actividades afines. Santiago: FAO, 1993. p.113-124. Informe sobre temas hídricos, n.1

Flaresso, J.A.; Gross, C.D.; Almeida, E.X. Época e densidade de semeadura de aveia preta (Avena strigosa) e azevém (Lolium multiflorum) no Alto Vale do Itajaí, SC. In: Reunião Anual da Sociedade Brasileira de Zootecnia, 35, 1998, Botucatu. Anais... Botucatu: SBZ, 1998. 4v. il. p.605-607.

Gomes, J.F.; Reis, J.C.L. Produção de forrageiras anuais de estação fria no litoral sul do Rio Grande do Sul. Revista Brasileira de Zootecnia, Viçosa, v.28, n.4, p.668-674, 1999.

Guideli, C.; Favoretto, V.; Malheiros, E.B. Produção de matéria seca de genótipos de milheto em diferentes épocas de semeadura e níveis de adubação nitrogenada. In: Reunião Anual da Sociedade Brasileira de Zootecnia, 35, 1998, Botucatu. Anais... Botucatu: SBZ, 1998. 4v. il. p.572-574

Hubbard, R.D.; Thomas, D.L.; Leonard, R.A.; Butler, J.L. Surface runoff and shallow ground water quality as affected by center pivot applied dairy cattle waste. Transactions of ASAE, St Joseph, v.30, n.2, p.430-437, 1987.

Leite, C.A.M.; Silva, O.M. A demanda de cafés especiais. In: Café: produtividade, qualidade e sustentabilidade. Viçosa: Imprensa Universitária, UFV, 2000. p.50-74.

Matos, A.T.; Lo Monaco, P.A.; Pinto, A.B.; Fia, R.; Fukunaga, D.C. Pollutant potential of wastewater from the coffee fruits processing. In Soares, A.A.; Saturnino, H.M. Environmental water: Competitive use and conservation strategies for water and natural resources. Brasília: ABID, 2001. p.158-165.
Moraes, A.; Groff, E.C.; Carvalho, P.C.F.; Hazard, L.; Mousset, C. Avaliação da produção de espécies forrageiras de inverno. In: Reunião Anual da Sociedade Brasileira de Zootecnia, 35, 1998, Botucatu. Anais... Botucatu: SBZ, 1998. 4v. il. p.307309

Paganini, W.S. Disposição de esgotos no solo (escoamento à superfície). São Paulo: Fundo Editorial da AESABESP, 1997. 232p.

Pereira, O.G. Produtividade do milho (Zea mays L.), do sorgo (Sorghum bicolor (L.) moench), da aveia (Avena sativa), do milheto (Pennisetum americanum L.) e do híbrido (S. bicolor $\mathrm{x} S$. sudanense), e respectivos valores nutritivos sob forma de silagem e verde picado. Viçosa, UFV, 1991. 86p. Dissertação Mestrado

Queiroz, F.M.; Matos, A.T.; Pereira, O.G.; Oliveira, R.A. The dry matter yield of forage-grass species in overland flow. In: Soares, A.A.; Saturnino, H.M. Environmental water: Competitive use and conservation strategies for water and natural resources. Brasília: ABID, 2001.p.166-172.

Silva, D.J. Análises de alimentos (métodos químicos e biológicos). 2 ed. Viçosa: UFV, 1998. 165p. il.

Soccol, C.R.; Leifa, F.; Woiciechowski, A.L.; Brand, D.; Machado, C.M.M.; Soares, M.; Christen, P.; Pandey, A. Experiência brasileira na valorização biotecnológica de subprodutos da agroindústria do café. In: Seminário Internacional sobre Biotecnologia na Agroindústria Cafeeira, 3, 1999, Londrina. Anais..., Londrina: UFPR, IAPAR, IRD, 2000. p.323-328. 